\title{
Changes in the phase composition in OPC and blended cement mortars due to carbonation
}

\author{
M. Maslehuddin, ${ }^{*}$ J. Shirokoff* and M. A. B. Siddiqui*
}

King Fahd University of Petroleum and Minerals

\begin{abstract}
The effect of carbonation on the phase composition in salt-contaminated $\left(0.8 \% \mathrm{Cl}^{-}\right.$and $\left.1.5 \% \quad \mathrm{SO}_{3}\right)$ and uncontaminated $O P C$ and blended cement mortar specimens exposed to elevated temperature is described. Changes in the phase composition were monitored using X-ray diffraction and differential thermal thermogravimetric analyses. Results indicated the transformation of cement hydration products to calcite in $O P C$, while calcite and aragonite were detected in the blended cements. The quantity of calcium carbonate in the contaminated cements was more than that in the uncontaminated specimens. The enhanced carbonation in the contaminated specimens may by attributed to: (i) an increase in the alkalinity of the pore solution; and (ii) changes in the morphology of the hardened cement, brought about by the chloride-sulfate contamination.
\end{abstract}

\section{Introduction}

Carbonation in concrete normally involves a chemical reaction between atmospheric carbon dioxide and the products of cement hydration. This reaction results in a significant reduction in the $\mathrm{pH}$ of the pore solution due to the removal of hydroxyl ions. Steinour has shown that virtually all of the cement hydrates react with carbon dioxide.' The main cement hydrates, i.e. calcium silicate hydrate $(\mathrm{C}-\mathrm{S}-\mathrm{H})$, calcium hydroxide $\left(\mathrm{Ca}(\mathrm{OH})_{2}\right)$ and various aluminate phases react to produce calcium carbonate, silica gel and hydrated aluminium and iron oxides. ${ }^{2}$ Based on differential scanning calorimetry (DSC) and Fourier Transform Infrared Spectroscopy (FITR), Sakai et al. indicated that $\mathrm{C}-\mathrm{S}-\mathrm{H}$ is decomposed to calcite and silica gel or to $\mathrm{C}-\mathrm{S}-\mathrm{H}$ with a low $\mathrm{Ca} / \mathrm{Si}$ ratio due to carbonation. ${ }^{3}$

The importance of carbonation, which is a slow process under natural conditions has grown in recent years owing to increased atmospheric pollution and the ageing of structures. While serveral studies have been conducted to evaluate the effect of carbonation at normal temperatures, data are lacking on the effect of

\footnotetext{
* Research Institute, King Fahd University of Petroleum and Minerals, Dhahran 31261, Saudi Arabia.
}

Paper received 29 June 1994; paper revised 16 January 1996; accepted 6 March 1996. temperature and chloride sulfate contamination on this process. Such a study is highly relevant to concrete structures serving in arid and semi-arid regions of the world, and marine structures in hot countries.

In this study, the effect of chloride and sulfate contamination and elevated temperature on the phase composition in ordinary Portland cement (OPC) and blended cement mortar specimens was evaluated using $\mathrm{X}$-ray diffraction (XRD) and differential thermal/ thermogravimetric (DTA/TG) techniques.

\section{Specimen preparation and techniques}

\section{Specimen preparation}

Cement mortar specimens $50 \mathrm{~mm}$ dia. $\times 75 \mathrm{~mm}$ height were prepared with a sand to cementitious materials ratio of $2 \cdot 0$ and water to cementitious materials ratio of 0.50 . In the blended cement mortar specimens, the pozzolanic materials were used partially to replace cement. In the fly ash cement mortar specimens, 20\% fly ash was used as a replacement of cement. In the silica fume cement mortar specimens, $10 \%$ cement was replaced with silica fume, while the blast furnace slag (BFS) cement contained $70 \%$ BFS and $30 \%$ OPC. The chemical compositions of OPC and pozzolanic materials are shown in Table 1.

The contaminated specimens contained $0 \cdot 8 \% \mathrm{Cl}^{-}$ and $1.5 \% \mathrm{SO}_{3}$, by weight of cement. The sulfate and 
Table 1. Chemical composition of cement and pozzolanic materials

\begin{tabular}{l|r|r|r|r}
\hline Constituent: wt \% & OPC & $\begin{array}{r}\text { Fly } \\
\text { ash }\end{array}$ & $\begin{array}{c}\text { Blast } \\
\text { furnace } \\
\text { slag }\end{array}$ & $\begin{array}{c}\text { Silica } \\
\text { fume }\end{array}$ \\
\hline $\mathrm{SiO}_{2}$ & $20 \cdot 52$ & $52 \cdot 3$ & $27 \cdot 7$ & $92 \cdot 5$ \\
$\mathrm{Al}_{2} \mathrm{O}_{3}$ & $5 \cdot 64$ & $25 \cdot 2$ & $12 \cdot 8$ & $0 \cdot 4$ \\
$\mathrm{Fe}_{2} \mathrm{O}_{3}$ & $3 \cdot 80$ & $4 \cdot 6$ & $1 \cdot 2$ & $0 \cdot 4$ \\
$\mathrm{CaO}$ & $64 \cdot 35$ & $10 \cdot 0$ & $44 \cdot 0$ & $0 \cdot 5$ \\
$\mathrm{MgO}$ & $2 \cdot 11$ & $2 \cdot 2$ & $8 \cdot 8$ & $0 \cdot 9$ \\
$\mathrm{SO}_{3}$ & $2 \cdot 10$ & $0 \cdot 6$ & $3 \cdot 1$ & $0 \cdot 5$ \\
$\mathrm{Loss}$ on ignition & $0 \cdot 70$ & $0 \cdot 4$ & $0 \cdot 9$ & $2 \cdot 6$ \\
$\mathrm{~K}_{2} \mathrm{O}$ & $0 \cdot 36$ & $0 \cdot 1$ & $0 \cdot 1$ & $0 \cdot 4$ \\
$\mathrm{Na}_{2} \mathrm{O}$ & $0 \cdot 19$ & $0 \cdot 1$ & $0 \cdot 4$ & $1 \cdot 1$ \\
$\mathrm{Na}_{2} \mathrm{O}$ equivalent & $0 \cdot 43$ & $0 \cdot 1$ & $0 \cdot 5$ & $1 \cdot 4$ \\
$\mathrm{C}_{3} \mathrm{~S}$ & $56 \cdot 70$ & - & - & - \\
$\mathrm{C}_{2} \mathrm{~S}$ & $16 \cdot 05$ & - & - & - \\
$\mathrm{C}_{3} \mathrm{~A}$ & $8 \cdot 52$ & - & - & - \\
$\mathrm{C}_{4} \mathrm{AF}$ & $11 \cdot 56$ & - & - & - \\
\hline
\end{tabular}

chloride ions were obtained using sodium chloride and sodium sulfate. The ingredients were mixed in a mor tar mixer until a uniform colour was obtained, after which they were poured into plastic moulds and lightly tapped to eliminate entrapped air. The plastic moulds were then sealed and the specimens left to cure at room temperature $\left(20^{\circ} \mathrm{C}\right)$ for 28 days. After curing, the specimens were removed from the moulds and placed in an exposure chamber until testing.

\section{Exposure conditions}

The mortar specimens were exposed to a controlled environment at constant temperature $\left(55^{\circ} \mathrm{C}\right)$, humidity (75\%) and $\mathrm{CO}_{2}$ content $(3 \%)$ for 54 weeks.

\section{Techniques}

$X$-ray diffraction. The X-ray diffraction technique was used to monitor the effect of carbonation on the phase composition of cement. This technique is useful in evaluating the reduction in calcium hydroxide content and the increase in the various forms of calcium carbonate. $^{2,4-6}$

$\mathrm{X}$-ray diffraction (XRD) analysis was performed using a Philips PW 1700 automated diffractometer with a monochromator and sample spinner. Diffraction patterns were generated on a vertical goniometer attached to a broad-focus X-ray tube with a copper target operating at $45 \mathrm{kV}$ and $30 \mathrm{~mA}$. The analysis is computer assisted so that the interplanar spacing values can be corrected for the instrument error function with reference to a silicon standard. The specimens were powdered with an agate pestle and mortar and sieved through a \#100 $(150 \mu \mathrm{m})$ sieve to collect the cement. A homogenous sample of this powder was packed into a sample holder and scanned from $4-40^{\circ} \mathrm{C} 2 \theta$ at a speed of $0.012 \theta / \mathrm{s}$. The phase indentification process involves matching peak intensity and peak position against a database of standard phases.
X-ray diffraction patterns for the neutralized and un-neutralized portions (those exhibiting no colour change, and pink, respectively, after spraying with phenolphthalein) were obtained to identify the compound composition.

Differential thermal analysis. Thermal analysis was conducted using a Netzch simultaneous thermal analyser (STA-429), which performs thermogravimetry and differential thermal analysis simultaneously. About $100 \mathrm{mg}$ of powdered specimen was tested with alumina as a reference material. The temperature was then raised at a uniform rate of $10^{\circ} \mathrm{C} / \mathrm{min}$, from room temperature to $1000^{\circ} \mathrm{C}$. In the thermograms, weight loss and differential temperature are plotted simultaneously.

\section{Results}

Figures 1 and 2 show the X-ray diffractograms of the un-neutralized and neutralized portions of uncontaminated OPC mortar, respectively. The main compounds were, quartz $\left(\mathrm{SiO}_{2}\right)$, portlandite $\left(\mathrm{Ca}(\mathrm{OH})_{2}\right)$, and calcite. The peak for portlandite in the neutralized portion was less intense than that in the un-neutralized portion. Similarly, the peak for calcite in the neutralized portion became slightly more significant than in the un-neutralized portion. X-ray diffractograms for the un-neutralized and neutralized OPC mortar contaminated with sodium chloride and sodium sulfate are shown in Figs 3 and 4, respectively. The un-neutralized portion contained quartz, calcite and portlandite, while peaks for quartz and calcite were evident in the neutralized portion. X-ray diffractograms for the neutralized and un-neutralized fly ash cement mortar contaminated with sodium chloride and sodium sulfate are shown in Figs 5 and 6, respectively. In the un-neutralized portion, X-ray peaks for quartz

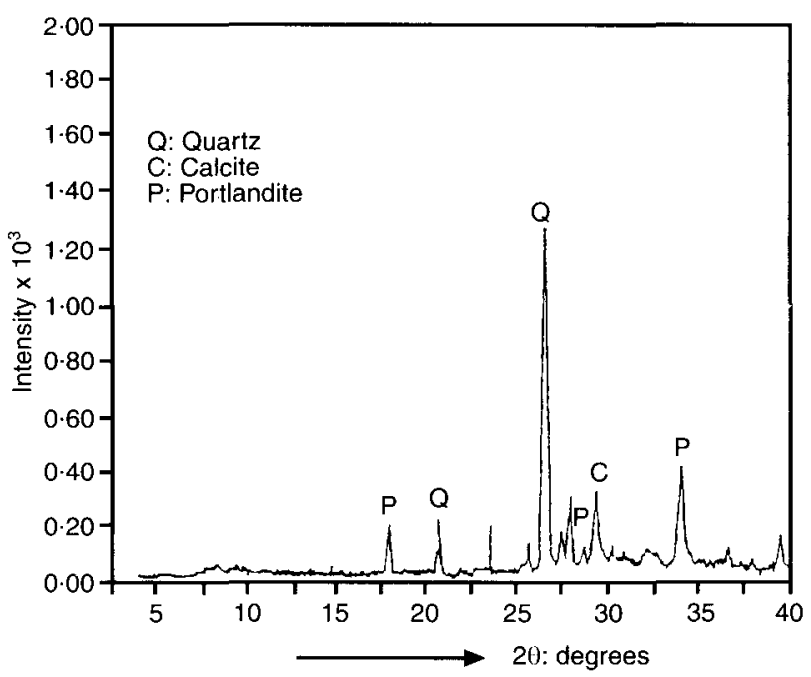

Fig. 1. X-ray diffractogram for un-neutralized $O P C$ mortar (no contamination)

Advances in Cement Research, 1996, 8, No. 32 




Fig. 2. X-ray diffractogram for neutralized $O P C$ mortar (no contamination)



Fig 3. X-ray diffractogram for un-neutralized $O P C$ mortar (contaminated with sodium chloride plus sodium sulfate)



Fig 4. X-ray diffractogram for neutralized OPC mortar (contaminated with sodium chloride plus sodium sulfate)

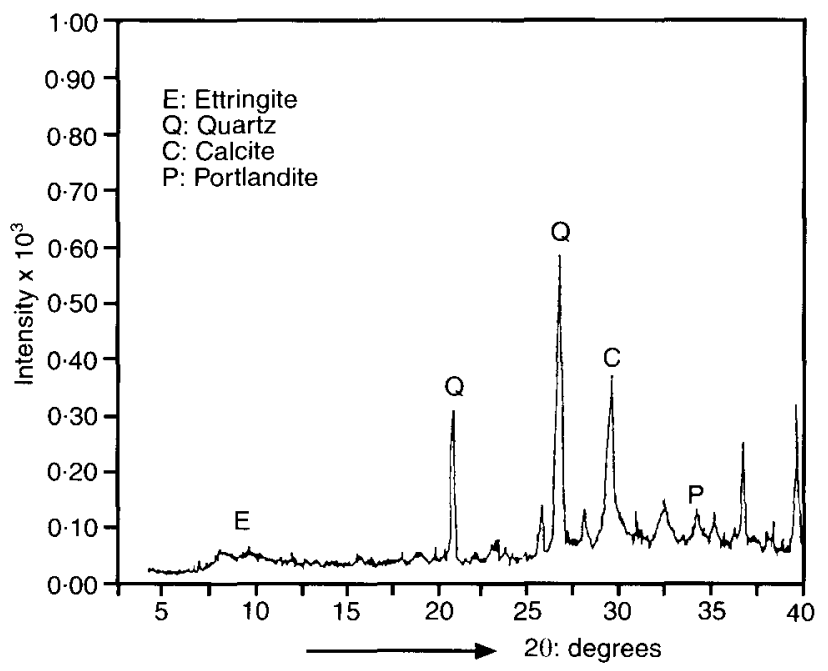

Fig. 5. X-ray diffractogram for un-neutralized fly ash cement mortar (contaminated with sodium chloride plus sodium sulfate)

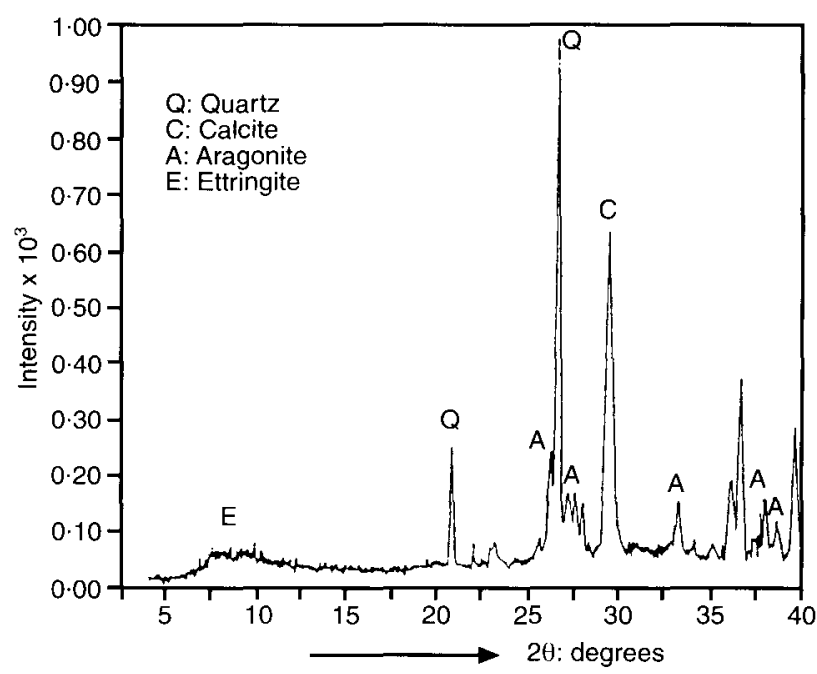

Fig. 6. X-ray diffractogram for neutralized fly ash cement mortar (contaminated with sodium chloride plus sodium sulfate)

and calcite were detected, while in the neutralized portion, peaks for quartz, calcite and aragonite were noted. X-ray diffractograms for the un-neutralized contaminated silica fume cement mortar (Fig. 7), indicate the presence of quartz and calcite only. The absence of portlandite may be attributed to the pozzolanic reaction between silica fume and calcium hydroxide. The X-ray diffractogram for the neutralized portion, Fig. 8, indicate the presence of quartz and calcite. The intensity of the calcite peak was slightly higher than that in the un-neutralized portion. X-ray diffractograms for the un-neutralized and neutralized contaminated blast furnace slag cement are shown in Figs 9 and 10 , respectively. The peaks for the un-neutralized portion (Fig. 9) indicate the presence of quartz and calcite, and a very small quantity of portlandite, while the $X$ ray diffractogram for the neutralized portion (Fig. 10) 




Fig. 7. X-ray diffractogram for un-neutralized silica fume cement mortar (contaminated with sodium chloride plus sodium sulfate)

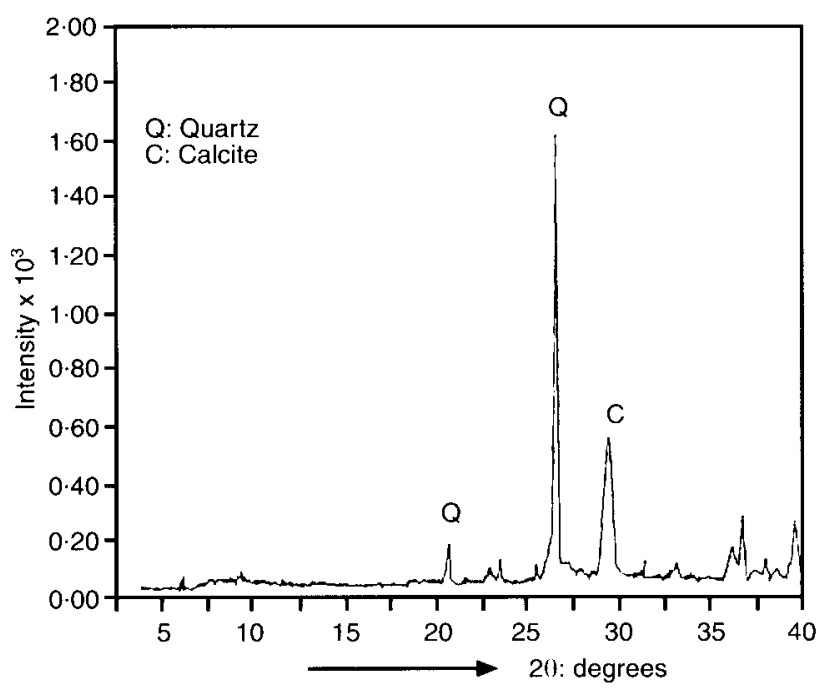

Fig. 8. X-ray diffractogram for neutralized silica fume cement mortar (contaminated with sodium chloride plus sodium sulfate)

indicates the presence of quartz, calcite and aragonite. It is interesting to note that the X-ray peaks for calcium chloroaluminate hydrate (Friedel's salt) were not detected in the contaminated specimens. This may be attributed to the reduction in the chloride-binding capacity of the cement hydration products, particularly $\mathrm{C}_{3} \mathrm{~A}$, due to the conjoint presence of chloride and sulfate salts. ${ }^{7}$

The DTA and TG curves for the un-neutralized and neutralized portions of the uncontaminated OPC mortar, typical of more than twelve such graphs developed in this investigation, are plotted in Figs 11 and 12, respectively. The DTA curve indicates the formation of endothermic peaks at $450^{\circ} \mathrm{C}$ and $850^{\circ} \mathrm{C}$ for



Fig. 9. X-ray diffractogram for un-neutralized blast furnace slag cement mortar (contaminated with sodium chloride plus sodium sulfate)



Fig. 10. X-ray diffractogram for neutralized blast furnace slag cement mortar (contaminated with sodium chloride plus sodium sulfate)

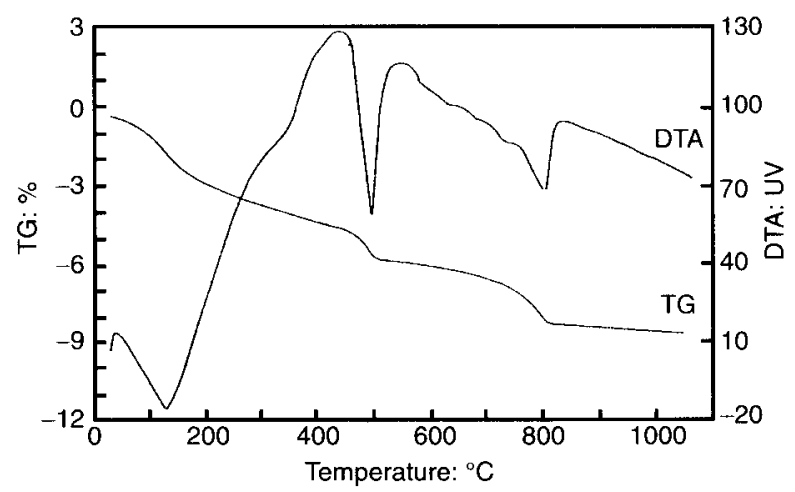

Fig. 11. DTA and TG curves for un-neutralized OPC mortar (no contamination)

Advances in Cement Research, 1996, 8, No. 32 




Fig. 12. DTA and TG curves for neutralized OPC mortar (no contamination)

$\mathrm{Ca}(\mathrm{OH})_{2}$ and $\mathrm{CaCO}_{3}$, respectively. The $\mathrm{Ca}(\mathrm{OH})_{2}$ and $\mathrm{CaCO}_{3}$, content in the uncontaminated and contaminated plain and blended cement mortar specimens, calculated from the TG curves, is summarized in Table 2. As expected, the amount of $\mathrm{Ca}(\mathrm{OH})_{2}$ in the neutralized portions was less than that in the unneutralized zones. Similarly, the amount of $\mathrm{CaCO}_{3}$ in the neutralized portion was more than that in the unneutralized zone. Further, the $\mathrm{CaCO}_{3}$ content in the neutralized portions of the contaminated specimens was more than that in similar parts of the uncontaminated specimens.

\section{Discussion}

The X-ray diffractograms for plain and blended cements (Figs 1-10) indicate the formation of calcium carbonate in both neutralized and un-neutralized zones. The presence of $\mathrm{CaCO}_{3}$ in the un-neutralized portions implies that $\mathrm{CO}_{2}$ has reacted with the cement hydration products in both zones. However, it did not progress to the extent of reducing the $\mathrm{pH}$ below the detectable limit of the phenolphthalein indicator $(\mathrm{pH}<10)$. Such a discrepancy in cabonation depth measurements by phenolphthalein test and thermogravimetry (TG) have been reported by Rahman and Glasser. According to them, the depth of carbonation measured by the TG method was somewhat greater than that obtained by the phenolphthalein test.

In the neutralized blended cement mortar specimens calcite and aragonite forms of $\mathrm{CaCO}_{3}$ were present, while in the OPC only calcite was detected. This indicates that in the absence of portlandite, other cement hydration products may be reacting with $\mathrm{CO}_{2}$ to produce $\mathrm{CaCO}_{3}$, the main constituent being $\mathrm{C}-\mathrm{S}-\mathrm{H}$. This supports the conclusions reached by others 9.10 and by Steinour,' who was shown that carbonation in the systems $\mathrm{CaO}-\mathrm{SiO}_{2}-\mathrm{H}_{2} \mathrm{O}, \mathrm{CaO}-\mathrm{Al}_{2} \mathrm{O}_{3}-\mathrm{H}_{2} \mathrm{O}$ and $\mathrm{CaO}-\mathrm{Al}_{2} \mathrm{O}_{3}-\mathrm{CaSO}_{4}-\mathrm{H}_{2} \mathrm{O}$ proceeds to completion, even in air, until silica and alumina are converted to hydrous oxides.

The data on $\mathrm{Ca}(\mathrm{OH})_{2}$ and $\mathrm{CaCO}_{3}$ (Table 2), determined by DTA and TG, indicated greater carbonation in the contaminated cement mortar specimens than in the uncontaminated specimens. The evidence of accelerated carbonation in the contaminated specimens can be appreciated from the fact that the $\mathrm{CaCO}_{3}$ formed in the neutralized portion of the uncontaminated OPC mortar specimen was $10.64 \%$ compared to $16.76 \%$ measured in the contaminated specimen (Table 2). Similarly, in the fly ash cement mortar specimens these values were $5 \cdot 2$ and $10.44 \%$, respectively.

The enhanced decomposition of cement hydration products in contaminated specimens may be attributed to an increase in the alkalinity of the pore solution due to the addition of $\mathrm{NaCl}$ and $\mathrm{Na}_{2} \mathrm{SO}_{4} \cdot{ }^{7}$ Kobayashi and Uno, ${ }^{1}$ investigating the effect of cement alkalinity on carbonation, reported that the rate of carbonation increases with the alkali content of cement. In a later work, they investigated the effect of cement alkalinity on carbonation in concrete specimens. ${ }^{12}$ The results of that study also indicated that the depth of carbonation was dependent on the water-cement ratio and the alkalinity of the cement. For mixes of similar water-cement ratio, the depth of carbonation was ob served to be higher in cement made with higher $\mathrm{Na}_{2} \mathrm{O}$ equivalent.

The accelerated carbonation in the contaminated specimens may also be attributed to the morphological changes brought about by their inclusion. Bensted ${ }^{13}$

Table 2. Calcium hydroxide and calcium carbonate content in contaminated and uncontaminated OPC and blended cement mortar specimens

\begin{tabular}{|c|c|c|c|c|c|}
\hline \multirow{2}{*}{ Cement } & \multirow{2}{*}{ Contamination } & \multicolumn{2}{|c|}{$\begin{array}{c}\mathrm{Ca}(\mathrm{OH})_{2}: \\
\% \text { hydrated material }\end{array}$} & \multicolumn{2}{|c|}{$\begin{array}{c}\mathrm{CaCO}_{3} \text { : } \\
\% \text { hydrated material }\end{array}$} \\
\hline & & Un-neutralized & Neutralized & Un-neutralized & Neutralized \\
\hline $\mathrm{OPC}$ & None & $5 \cdot 48$ & $1 \cdot 83$ & $4 \cdot 68$ & $10 \cdot 64$ \\
\hline Fly ash & None & $3 \cdot 13$ & $3 \cdot 71$ & $2 \cdot 30$ & $5 \cdot 20$ \\
\hline $\mathrm{OPC}$ & $\mathrm{Cl}+\mathrm{SO}_{4}$ & $6 \cdot 10$ & $1 \cdot 70$ & $1 \cdot 70$ & $16 \cdot 70$ \\
\hline Fly ash & $\mathrm{Cl}+\mathrm{SO}_{4}$ & 1.98 & $4 \cdot 48$ & $4 \cdot 48$ & $10 \cdot 44$ \\
\hline Silica Fume & $\mathrm{Cl}+\mathrm{SO}_{4}$ & -- & $7 \cdot 10$ & - & $13 \cdot 60$ \\
\hline BFS & $\mathrm{Cl}+\mathrm{SO}_{4}$ & - & $5 \cdot 30$ & - & $13 \cdot 20$ \\
\hline
\end{tabular}


indicated that enhanced carbonation in cements with higher alkalinity can be related to the coarser pore structure formed in the presence of alkalis. He observed that alkalis accelerate the hydration of Portland cement. This results in greater quantities of hydrates, such as C-S-H and ettringite, being formed at earlier stages of the hydration process than under nonaccelerated conditions. The accelerated hydration results in relatively greater heterogeneities in the microstructure developed during hydration. Mori et al., ${ }^{14}$ as quoted by Jawed and Skalny, 15 indicated that the specific surface area of the hydrated $\mathrm{C}_{3} \mathrm{~S}$ decreased at all ages in the presence of alkalis, and the morphology and microstructure also changed. The microstructure of C-S-H became coarser; particles grew from the grain surface into the $\mathrm{NaOH}$ solution. In the presence of $\mathrm{Na}_{2} \mathrm{SO}_{4}$, fine acicular $\mathrm{C}-\mathrm{S}-\mathrm{H}$ particles (probably containing $\mathrm{SO}_{4}{ }^{-}$ions) densely covered the $\mathrm{C}_{3} \mathrm{~S}$ grain surface, but did not grow extensively outward from the surface. The coarsening of the pore structure due to inclusion of sodium chloride and sodium sulfate has also been observed through mercury intrusion porosimetry by the authors. ${ }^{16}$ The total pore volume in the contaminated specimens was more than that in the uncontaminated specimens (Fig. 13).

Another consequence of chloride-sulfate contamination is moisture retention leading to the formation of $\mathrm{CaCO}_{3}$. The moisture retained within the pores may enhance the carbonation process. Glass et al., indicate that low levels of chloride contamination increase the ionic conductivity, whereas higher levels favour moisture rentention.

\section{Conclusions}

The X-ray diffractograms for the neutralized and un-neutralized portions of OPC and blended cement mortar specimens indicated the presence of quartz $\left(\mathrm{SiO}_{2}\right)$, portlandite $\left(\mathrm{Ca}(\mathrm{OH})_{2}\right)$, and $\mathrm{CaCO}_{3}$. The



Fig. 13. Pore size distribution in the contaminated and uncontaminated cement paste specimens quantity of $\mathrm{CaCO}_{3}$, present either in the form of calcite or aragonite, was more in the neutralized specimens than in the un-neutralized portions.

The DTA and TG curves also indicated greater carbonation in the contaminated specimens. This trend was observed both in OPC and blended cements. In $\mathrm{OPC}$, the $\mathrm{Ca}(\mathrm{OH})_{2}$ peaks tended to diminish with carbonation. In the blended cements, the depth of $\mathrm{Ca}(\mathrm{OH})_{2}$ peaks was very insignificant, indicating the consumption of this cement hydration product due to pozzolanic reaction. An increase in the $\mathrm{CaCO}_{3}$ peak in blended cements indicates that other cement hydration products may be reacting with $\mathrm{CO}_{2}$.

Enhanced carbonation in the contaminated specimens may be attributed to changes brought about in the structure of the hardened cement paste due to the inclusion of $\mathrm{NaCl}$ and $\mathrm{Na}_{2} \mathrm{SO}_{4}$. Inclusion of these salts accelerates cement hydration, which results in relatively greater heterogeneities in the microstructure, which aid the ingress of $\mathrm{CO}_{2}$.

\section{Acknowledgement}

The authors acknowledge the support of this research by the Research Institute, King Fahd Univer sity of Petroleum and Minerals, Dhahran, Saudi Arabia.

\section{References}

1. Steinour, H. Some effects of carbon dioxide on mortars and concrete - discussion. J. Amer. Concr. Inst., 1959, Feb. 394401.

2. Baird T., Cairn-Smith, G. and Snell, D. Morphology and carbon dioxide uptake in tobermorite gel. J. Colloidal Interface Sci., 1975, 50, No. 2, Feb., 387-391.

3. Sakal, E., Kosuge, K., Teramura, S. and Nakagawa, K. Carbonation of expansive concrete and change of hydration products. ACI Special Publication SP-126, 1992, pp. 989-999.

4. HAMADA, M. Neutralization of concrete and corrosion of reinforcing steel. Proc. Fifth Int. Symp. on the Chemistry of Cement, Tokoyo, 1968, pp. 343-368.

5. OHGishi, S. and ONO, H. Study to estimate depth of neutralization in concrete members. Cement Association of Japan Review, 1983, pp. 168-170.

6. KoKUbU, M. and Nagataki, S. Carbonation and corrosion of reinforcement in fly ash concrete. RILEM Symp. on Concrete Durability, Pt. 2, 1969, pp. 71-79.

7. Maslehuddin, M., Rasheeduzzafar, Page, C. L., Al-Mana, A. I. and AL-TAYYIB, A. J. Effect of temperature and sulfate contamination on the chloride binding capacity of cement. Proc. Fourth Int. Conf. on Deterioration and Repair of Concrete in the Arabian Gulf, Bahrain, October, 1993, pp. 717-734.

8. Rahman, A. A. and Glasser, F. P. Comparative studies of the carbonation of hydrated cements. Adv Cem. Res., 1989, 2, No. 6, pp. 49-54.

9. LEA, F. M. The chemistry of cement and concrete, Edward Arnold, London, 1935, p. 174.

10. STEOPE, A. Zement, 1935, 24, 795

11. KobaYASHI, K. and UNO, Y. Influence of alkaii on carbonation of concrete, part 1, preliminary tests with mortar specimens. Cem. Concr. Res., 1989, 19, No. 5, 821-826.

12. KobAYAshi, K., and UNO, Y. Influence of alkalies on carbonation 
of concrete part 2 - influence of alkali in cement on rate of carbonation of concrete. Cem. Concr. Res., 1990, 20, No. 4 , 619-622.

13. BENSTED, J. A discussion of the paper influence of alkali on carbonation of concrete, part 2, influence of alkali in cement on rate of carbonation of concrete. Cem. Concr. Res., 1991, 21, 675 .

14. MORI, H., et al. Revien, 15th General Meeting, Cement Association, Japan, 1961, p. 43.

15. JAWED, I. and SkALny, J. Alkalies in cement: a review - II Effects of alkalies on hydration and performance of Portland cement. Cem. Concr. Res., 1978, 8, No. 1, 37-52.

16. Basunbal, I. A., Khan, C. N. S. A. and Maslehuddin, M. Temperature and contamination effect on strength and porosity in plain and blended cements, to be published.

17. Glass, G. K., PAGe, C. L. and Short, N. R. Factors affecting the corrosion rate of steel in carbonated mortars. Corros. Sci. 32, No. 12, 1283-1294.

Discussion contributions on this paper should reach the editor by 28 April 1997 